\title{
Developing Planning-Level Drainage Solutions in Large, Multi-Jurisdictional Watersheds
}

\author{
George Remias, John Aldrich, Michael A. Gregory, Jeffrey E. Duke \\ and Frank Greenland
}

In October 2000, the Northeast Ohio Regional Sewer District (NEORSD or District) began the Regional Intercommunity Drainage Evaluation (RIDE) Study of 27 urban watersheds, representing a 414 square mile. $\left(1069 \mathrm{~km}^{2}\right)$ area within the metropolitan Cleveland area. The study area encompasses all or part of 60 communities that are located either within the District's service area or in an adjoining watershed. Some challenges common to large, multijurisdictional studies were encountered over the course of the RIDE Study. The purpose of this chapter is to highlight, using a case study in Ohio, how these challenges were addressed for the development of regional, planninglevel drainage solutions in multi-jurisdictional watersheds.

\subsection{Introduction}

In October 2000, the Northeast Ohio Regional Sewer District (NEORSD or District) began the Regional Intercommunity Drainage Evaluation (RIDE) Study of 27 urban watersheds, representing a 414 sq. mi. $\left(1069 \mathrm{~km}^{2}\right)$ area within the metropolitan Cleveland area. This area is shown in Figure 14.1 and encompasses all or part of 60 communities that are located either within the District's service area or in adjoining watersheds. The key goals of the RIDE Study are:

- Development of planning-level solutions and costs for alleviation of intercommunity drainage problems,

Remias, G., J. Aldrich, M. Gregory, J.E. Duke and F. Greenland. 2005. "Developing Planning-Level Drainage Solutions in Large, Multi-Jurisdictional Watersheds." Journal of Water Management Modeling R223-14. doi: 10.14796/JWMM.R223-14.

(C) CHI 2005 www.chijournal.org ISSN: 2292-6062 (Formerly in Effective Modeling of Urban Water Systems. ISBN: 0-9736716-0-2) 
- Production of comprehensive intercommunity storm drainage system mapping using Geographic Information Systems (GIS) to consolidate data for future use,

- Development of tools to assist District service area communities in complying with EPA National Pollutant Discharge Elimination System (NPDES) Phase II Storm Water Regulations, and

- Collection and management of data needed to support a regional storm water management program.

Because of the overall size of study area and number jurisdictions, the RIDE Study incurred numerous challenges, including the following: (i) how to approach multi-jurisdictional planning, (ii) data management approaches to support study and maintain consistency, (iii) how to define drainage problems, and (iv) developing watershed-wide approaches to provide more cost-effective solutions.

The purpose of this chapter is to highlight how these challenges were addressed during the RIDE study for the development of regional, planninglevel drainage solutions in multi-jurisdictional watersheds.

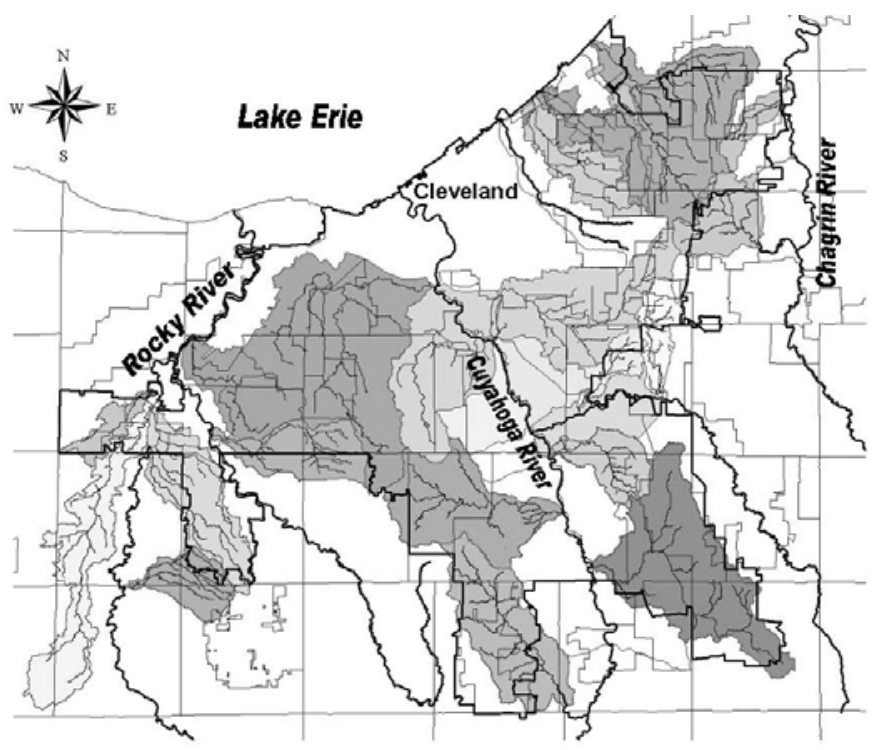

Figure 14.1 The RIDE Study area covers 414 sq. mi. $\left(1070 \mathrm{~km}^{2}\right)$ in the metropolitan Cleveland area. 


\subsection{How to Approach Multi-jurisdictional Planning}

A multi-jurisdictional study area contains multiple entities, each with varying degrees of authority, budget, expertise, objectives, and sources of information. An opportunity may exist for those entities within the study area that may have either a legal requirement or vested interest to address drainage related issues to work in unison. The following paragraphs discuss some of the key areas where the RIDE Study project team was successful at maximizing the collection and information sharing process, reducing overlapping effort, and minimizing situations which may have resulted in unnecessary conflict.

\subsubsection{Build Partnerships to Achieve Common Goals}

While different entities may have varying objectives for their respective projects, some common goals may exist whereby resources from each entity can be used in accomplish a similar task. One common goal between the RIDE Study and another entity was floodplain preservation, see Figure 14.2.

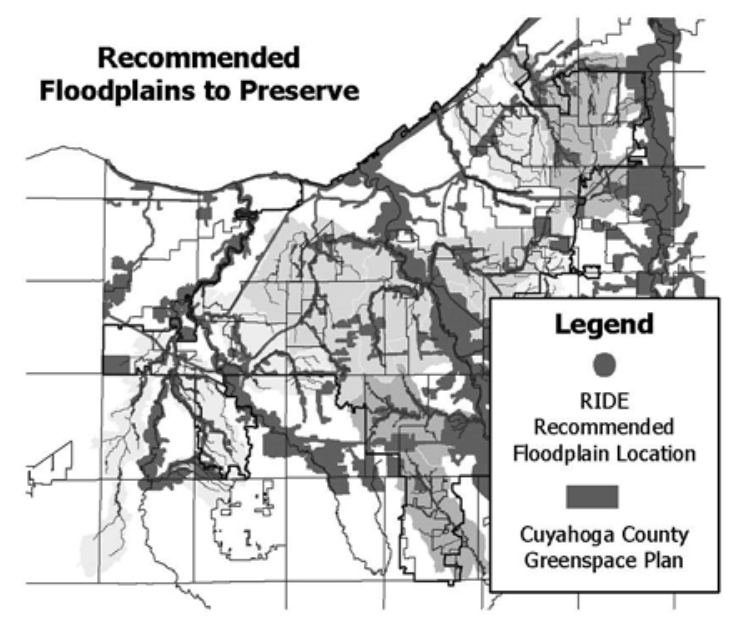

Figure 14.2 Example of common goal between RIDE Study and Cuyahoga County Greenspace Plan.

The RIDE Study recommended the preservation of floodplains to prevent flooding of structures under both existing and future conditions. The 
Cuyahoga County Greenspace Plan wanted to purchase property to increase recreational areas and natural settings. Recognizing the common goal the entities built a partnership to reduce duplicate effort and work together to accomplish the preservation and purchasing of floodplains within the RIDE study area

\subsubsection{Work in Concert with Watershed Groups}

Watershed groups have grown in popularity within the region, see Figure 14.3. Almost the entire RIDE study area has a representative watershed group that is interested in drainage-related topics. Although the groups vary by overall objectives, total number of members, professional and political backgrounds, funding sources, and years of existence, they commonly consist of individuals interested in drainage related issues for a watershed.

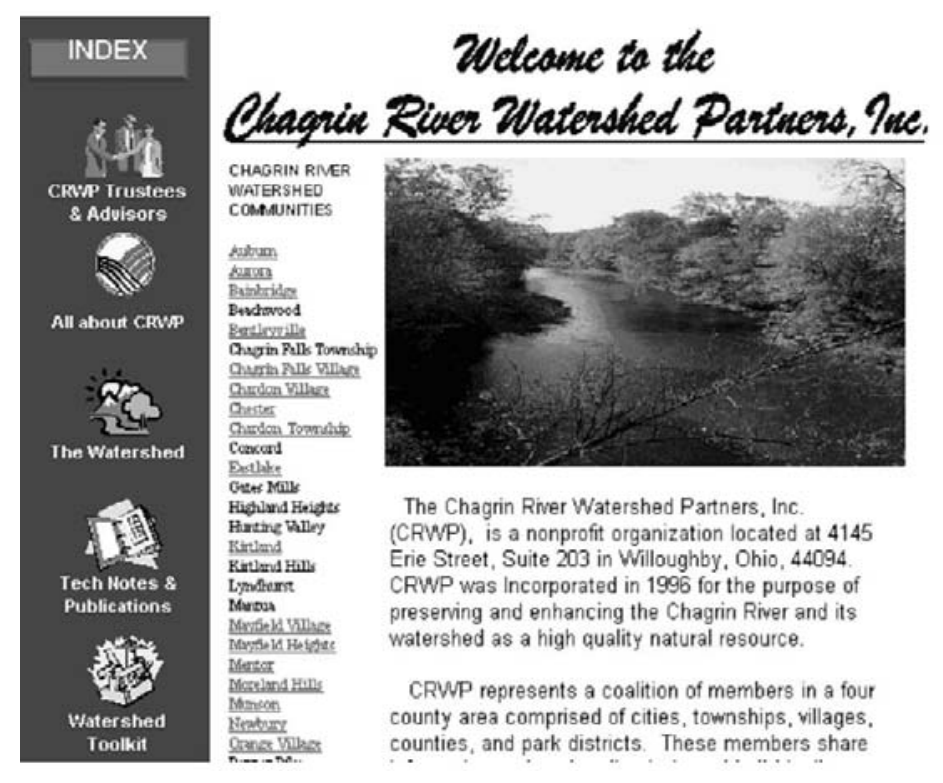

Figure 14.3 Watershed Group within RIDE Study area.

Political representation, including City, County, and regional officials typically make up a watershed group. Therefore, there is an advantage to work in concert with watershed groups in terms of establishing public 
education and public involvement, gaining public buy-in to the decision making process, locating funding sources, and reducing duplicate efforts to accomplish similar tasks.

\subsubsection{Identify Data Sources and Collect Data Objectively}

It is important to collect existing information to gain a better understanding of the current problems and previous solutions and to better understand where data gaps exist. Three primary sources of information were collected during the RIDE Study:

- Community Interviews - Each of the 60 communities in the Study Area was contacted by the project team and an interview was arranged for those communities interested in information sharing.

- Field Reconnaissance - Nearly 200 miles of stream were either walked to identify existing drainage problems or had drive-by visits to the culverts and detention ponds to collect information on the existing drainage structures and stream condition.

- Previous Studies - In areas where a drainage study previously was conducted the information was collected, including maps, location of drainage problems and recommended solutions to minimize duplicating efforts that addressed the RIDE Study project objectives.

Collecting data objectively is integral to better understanding what information exists. For example, during the RIDE study each community was interviewed independently. This focused approach encouraged the communities to share information, opinions, and ideas regarding drainage related topic compared to the potential for fewer opinions and ideas being shared if communities in conflict attended the same meeting.

\subsubsection{Package Results to Promote Coordination}

With 27 different watersheds and 60 communities it was critical to effectively package project deliverables in a manner that facilitated understanding for a vast audience. The results of the study were packaged into seven drainage areas and presented in Figure 14.4. The drainage areas were selected to promote coordination amongst the communities within the study area, to help illustrate that watersheds are not defined by community boundaries, and to reinforce that inter-relationships exist amongst the communities. 
To improve the overall organization and understanding of information and results over the course of the project, a project team member was assigned responsibility for each drainage area. Responsibilities included information collection, understanding and identifying drainage problems, evaluating alternative solutions, and developing a drainage area report.

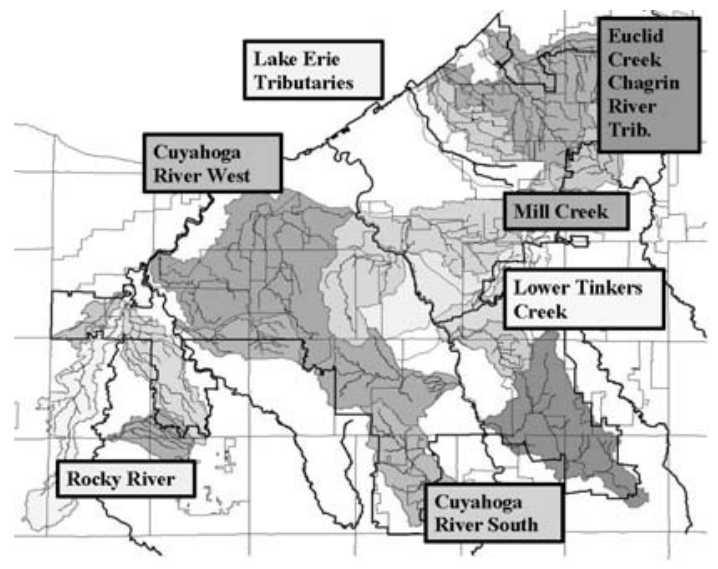

Figure 14.4 Summary of RIDE drainage areas.

\subsection{Data Management Approaches to Support Study and Maintain Consistency}

The overall volume of information collected for a large multi-jurisdictional watershed is both substantial and diverse. It's important that the information collected is properly organized and initially checked for consistency and accuracy prior to generating project deliverables. The following paragraphs discuss the process implemented during the RIDE study to facilitate consistency and accuracy across the study area.

Table 14.1 summarizes the data required for the RIDE Study. Significant amounts of existing digital and paper data were collected from the District; various Regional, State, and Federal agencies; and the communities within the RIDE Study Area. While some information was readily available at the beginning of the Study, e.g. contour maps, several sources of data had never been either collected, e.g. field measured culvert dimensions along tributaries or open channel cross-sections, or an updated version had yet to be provided, 
e.g. existing and future land cover maps. Additionally, other data was collected specifically for the RIDE Study, e.g. high water marks and flow monitoring data.

Table 14.1 Data categories to address RIDE.

\begin{tabular}{cc}
\hline RIDE Study Needs & Data Category \\
\hline Hydrologic & Topography \\
Characteristics & Existing and Future \\
& Land Cover \\
& Soil Properties \\
Hydraulic & Storm Sewers \\
Characteristics & Open Channels \\
& Stream Crossings \\
& Detention Facilities \\
Monitoring Data & Rainfall \\
& Flow \\
Problem Locations & High Water Marks \\
and Characteristics & Flooding \\
& Erosion \\
& Sedimentation and \\
Programmatic Data & Debris \\
& Floodplain Management \\
& Land Development \\
& Practices \\
& Operation and \\
& Maintenance \\
& Financial \\
\hline
\end{tabular}

The collected data varied significantly. For example information collected included paper maps and electronic maps. Land cover categories varied by community and ranged from a few categories to a few dozen. The level of accuracy provided also varied, e.g. location of storm sewers, the year the information was updated, etc. Electronic data varied by coordinate system and available attribute information, etc. Multiple sources also provided varying information for the same location (e.g. County vs. Community land cover data).

In order to promote consistency throughout the study area, the following verification/validation approach was implemented:

- Collect Existing Data - make sure information relevant to the study was collected from each of the respective data sources.

- Convert Data to Defined Project Standards - ensure the information was reviewed in a standard coordinate system, 
naming convention, and information was organized using standard fields, e.g. pipe size, length, material, etc.

- Conduct Quality Control - validate pipe sizes, lengths, material, invert elevations and update the information when warranted, e.g. revise 300-ft (92 m) diameter pipe with 3-ft (0.9).

- Utilize Final Product for Project Deliverables - maps and databases were utilized across the study area to ensure consistency, e.g. maps indicating the extent of the intercommunity drainage system, field forms and photos indicating the type of information collected, etc.

This approach helped improve the overall understanding of both the quality and coverage of existing information and helped focus the efforts to collect additional information. It also facilitated generating deliverables that covered the entire RIDE study area in a consistent manner, e.g. a basemap that illustrated the extent of the intercommunity drainage system.

\subsection{How to Define Drainage Problems}

Flooding, erosion, and debris problems represent an ongoing intercommunity risk to public safety and property. Drainage problems were identified through community interviews and/or field reconnaissance surveys conducted under the RIDE Study and their severity was quantified through observations and hydrologic/hydraulic evaluation of the watershed. This section summarizes the problem definition methodology used for the RIDE Study.

\subsubsection{Determine if Problem is Intracommunity or Intercommunity}

The RIDE Study focused on addressing intercommunity problems, so defining the difference between an intercommunity and intracommunity problem was critical for the project. The RIDE Study defines an intercommunity problem as:

- a problem caused by inadequate capacity in an intercommunity drainage system (i.e. a drainage system conveying flow from two or more communities), or

- an intercommunity system with inadequate capacity for communities to solve intracommunity problems. 


\subsubsection{Characterize the Problems by Type}

The definition of a problem can be very subjective. Therefore, to ensure consistency across the study area, criteria were developed for three types of problems: flooding, streambank erosion, and debris. If a problem met the RIDE criteria it was identified as a problem to be addressed under the RIDE Study. The criteria developed for the three types of problems are:

1. Flooding of residential, commercial, and industrial areas, and/or transportation routes creating public safety hazards, endangering public or private property, and/or disrupting the normal conduct of business, see Figure 14.5.

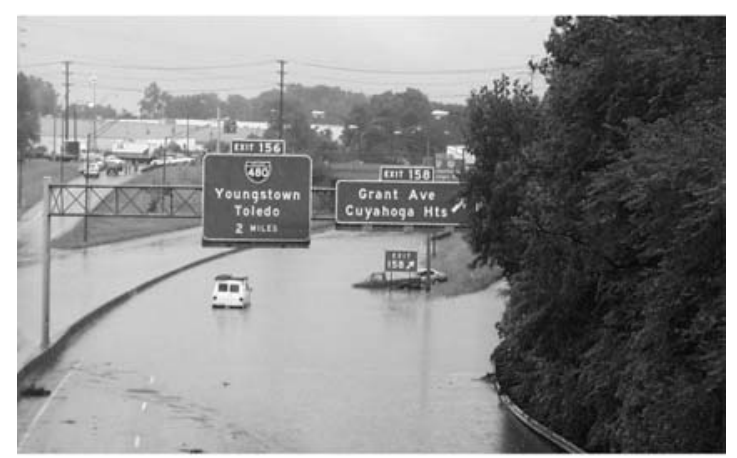

Figure 14.5 Example of RIDE flooding problem.

2. Streambank erosion that could pose a severe threat to public safety, public or private property, and/or the structural stability of existing utilities, see Figure 14.6.

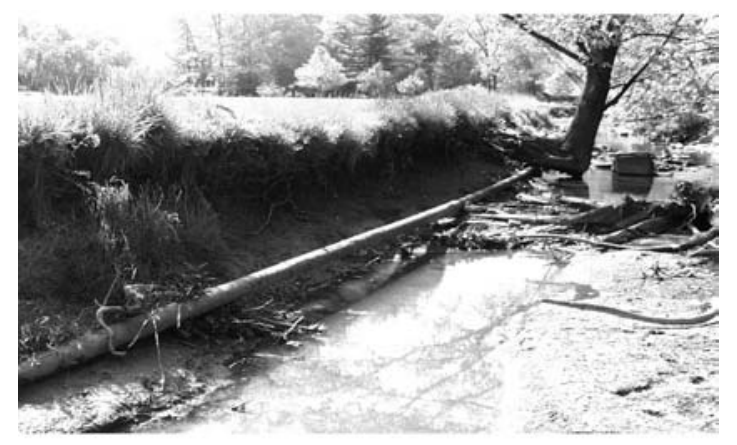

Figure 14.6 Example of RIDE streambank erosion problem. 
3. Debris accumulation, drainage restrictions, or other hydraulic conditions that could pose a severe threat to public safety, and/or public or private property, see Figure 14.7.

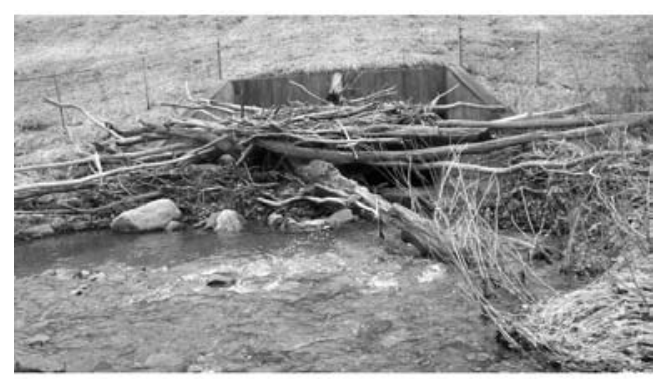

Figure 14.7 Example of RIDE debris problem.

\subsubsection{Quantify the Severity of the Problem}

Level of service goals were defined and applied uniformly across the RIDE Study area for intercommunity storm water management. Table 14.2 lists these methods for quantifying drainage problems, which consist of specific frequency and severity criteria for various watershed features.

Table 14.2 Methods for quantifying drainage problems.

\begin{tabular}{|c|c|c|c|c|}
\hline Type of Problem & Objective & Frequency & Severity & Extent \\
\hline Building Flooding & $\begin{array}{l}\text { Keep away from } \\
\text { foundation }\end{array}$ & 25-year & $\begin{array}{l}\text { Moderate: } 0-2 \mathrm{ft} . \\
\text { Severe: }>2 \mathrm{ft} .\end{array}$ & $\begin{array}{l}\text { Number of } \\
\text { potentially } \\
\text { inundated } \\
\text { buildings }\end{array}$ \\
\hline Roadway & Keep below road & & Moderate: $0-8$ & Length of \\
\hline Flooding & surface & & & roadway \\
\hline Local & & 10-year & Impassable: $>8$ & flooded \\
\hline Arterial & & 25-year & in. & Number of \\
\hline Freeway & & 50-year & & impassable \\
\hline Railroad & & 50-year & & roadways \\
\hline Property Flooding & Preserve Floodplain & 25-year & N/A & N/A \\
\hline Streambank & & 2-year & N/A & N/A \\
\hline \multicolumn{5}{|l|}{ Erosion } \\
\hline Threatens & Protect Structure & & & \\
\hline Structure & & & & \\
\hline Threatens & Preserve Floodplain & & & \\
\hline Property & & & & \\
\hline $\begin{array}{l}\text { Sedimentation and } \\
\text { Debris Control }\end{array}$ & $\begin{array}{l}\text { Remove to prevent } \\
\text { structure flooding }\end{array}$ & 25-year & N/A & N/A \\
\hline
\end{tabular}




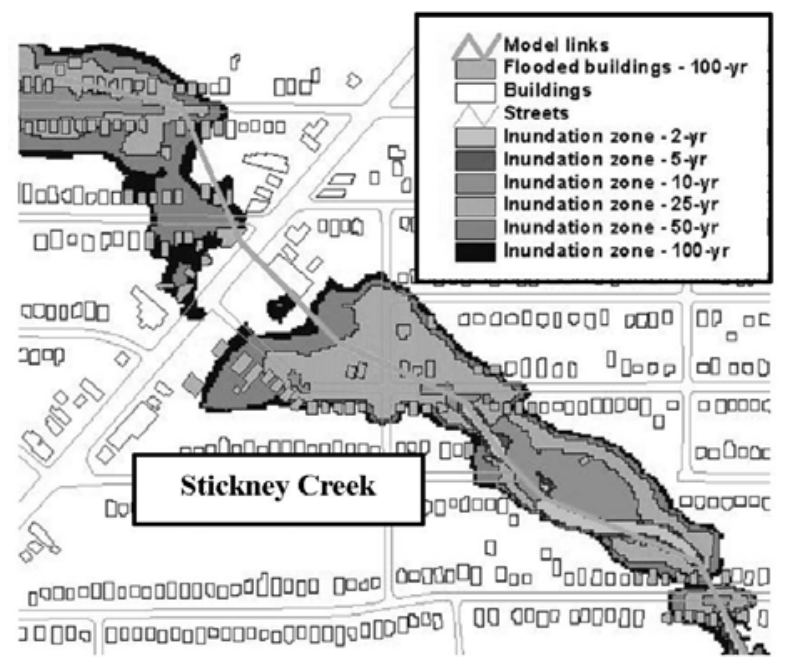

Figure 14.8 Quantifying problem severity.

Local and regional storm water management criteria both inside and outside the RIDE Study area were reviewed and compared prior to developing the severity and frequency criteria. Figure 14.8 illustrates how the severity of flooding was quantified and evaluated during the RIDE study along a modeled reach for a series of design storms. Not all drainage issues were considered to be problems. Rather, drainage issues were deemed to be problems when they met the severity and frequency criteria defined for the RIDE study. Severity and frequency were quantified through field observations and hydraulic modeling studies in the following manner:

- Building Flooding Severity was defined by the number of buildings where flooding reaches the building foundation, the depth of water at each building, and the frequency that buildings are threatened by flooding.

- Roadway Flooding Severity was defined by the type of roadway, the length of roadway flooded, the frequency of flooding, and the number of locations where roadways become impassable during a flood event.

- Streambank Erosion Severity was defined through field observations, predictions of accelerated flow velocity, frequency of reaching "bankfull" conditions, and structures, roadways, and 
infrastructure under an immediate threat of damage due to bank erosion.

- Debris Severity was defined based upon observed quantities of debris, potential to cause blockage of drainage structures, and potential for building flooding if these structures were to become obstructed.

An extensive sensitivity analysis of the severity and frequency criteria was not conducted during the RIDE study, but initial comparisons indicated that altering the frequency for local roadway flooding criteria (e.g. 10-y to 100-y) or severity of building flooding (Severe $>2 \mathrm{ft}$. to $>4 \mathrm{ft}$., or $>0.6 \mathrm{~m}$ to $>1.2 \mathrm{~m}$ ) from the criteria described in Table 14.2 appeared to alter the study results significantly. The primary reason for the variations are a direct result of many City storm water management ordinances, which require local roadway culverts to be sized to pass for much smaller storms (e.g. 5-y to 10-y), and the location of several structures along tributaries, which are built near or at the local roadway elevation. Therefore, during less frequent storms local roadway culverts surcharge resulting in roadway overflows, which in turn lead to the flooding of structures at or near the depth of the overflow.

\subsubsection{Define the Extent of the Problem}

Once the problems that met the RIDE Study criteria were identified, the next step was to determine how to better organize the problems. For example, several buildings and roads may flood along a channel reach, but may be the result of a single undersized culvert. Furthermore, multiple problem locations may exist within a short channel reach, but it may be difficult to define where one problem location begins and another ends.

The RIDE study organized the problems into problem reaches, which could consist of several problem locations, e.g. flooded houses or flooded roads. Figure 14.9 illustrates an example of a RIDE study problem reach.

\subsubsection{Review the Results}

The problems that met the criteria described above were evaluated to determine whether they resulted in a proper representation of problems within the RIDE study area. During the RIDE Study, drainage problems were defined for existing or projected future conditions along 535 miles of the intercommunity drainage system (i.e., the system of open channels, closed 
conduits, and detention facilities receiving drainage from more than one community).

Drainage problems were identified based on community interviews within the RIDE Study area and field reconnaissance surveys along 289 miles of the intercommunity drainage system. Figure 14.10 shows the location of the 476 drainage problem areas identified during the RIDE Study.

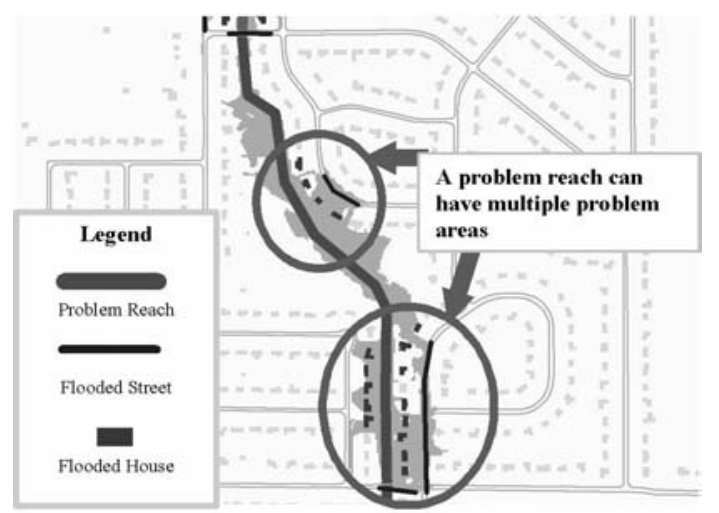

Figure 14.9 Example of RIDE problem reach.

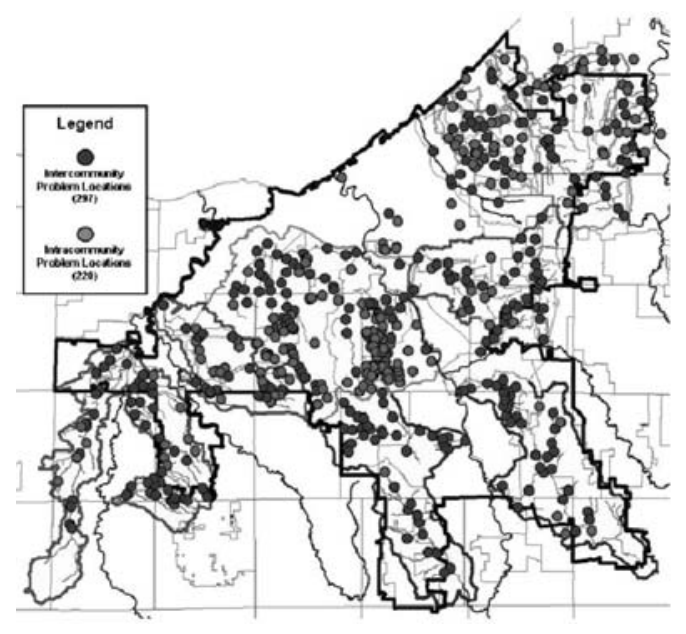

Figure 14.10 Of the 476 total problem locations within the RIDE Study area, 273 represent intercommunity problems. 
Further evaluation of these problems determined that only 273 of these problems were intercommunity problems, while the rest occur within local, intracommunity drainage systems. In general, more than one problem type often occurs within each problem area.

Figure 14.11 illustrates the distribution of the 128 flooding problems, 229 erosion problems, and 119 debris problems along intercommunity drainage systems within the RIDE Study area. Out-of-bank flooding that does not threaten a building or roadway was generally not considered to be a "problem." Instead, the RIDE Study generally considered this to be valuable floodplain storage that should be preserved to prevent increased flooding elsewhere in the watershed. In addition, the RIDE Study does not provide specific solutions to intracommunity drainage system problems (e.g. smallsized local storm drains, curb inlets, manholes, roadside ditches, and culverts).

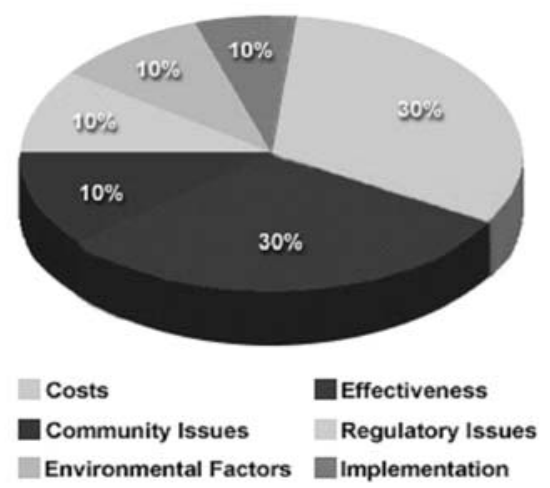

Figure 14.11 Alternative evaluation criteria and weighting factors used in the RIDE Study.

\subsection{Developing Watershed Wide Approaches to Provide More Cost-Effective Solutions}

Watershed boundaries typically span multiple jurisdictional boundaries, so an intracommunity perspective may not identify the overall cause of the problem or the optional types and locations of solutions. The RIDE Study evaluated a range of structural and non-structural solutions to solving drainage problems in addition to recommending steps to prevent future problems from occurring. 


\subsubsection{Intercommunity Drainage Solutions to Problems Presenting an Immediate Threat}

Planning-level solutions were developed to alleviate intercommunity drainage problems that present an immediate threat to structures, roadways, and infrastructure and included programmatic recommendations for preserving the capacity and integrity of the intercommunity drainage system. Solutions were developed with consideration of hydrologic and hydraulic modeling results, regulatory requirements, and industry best practices and included both structural and non-structural improvement alternatives.

Table 14.3 Summary of RIDE drainage problems.

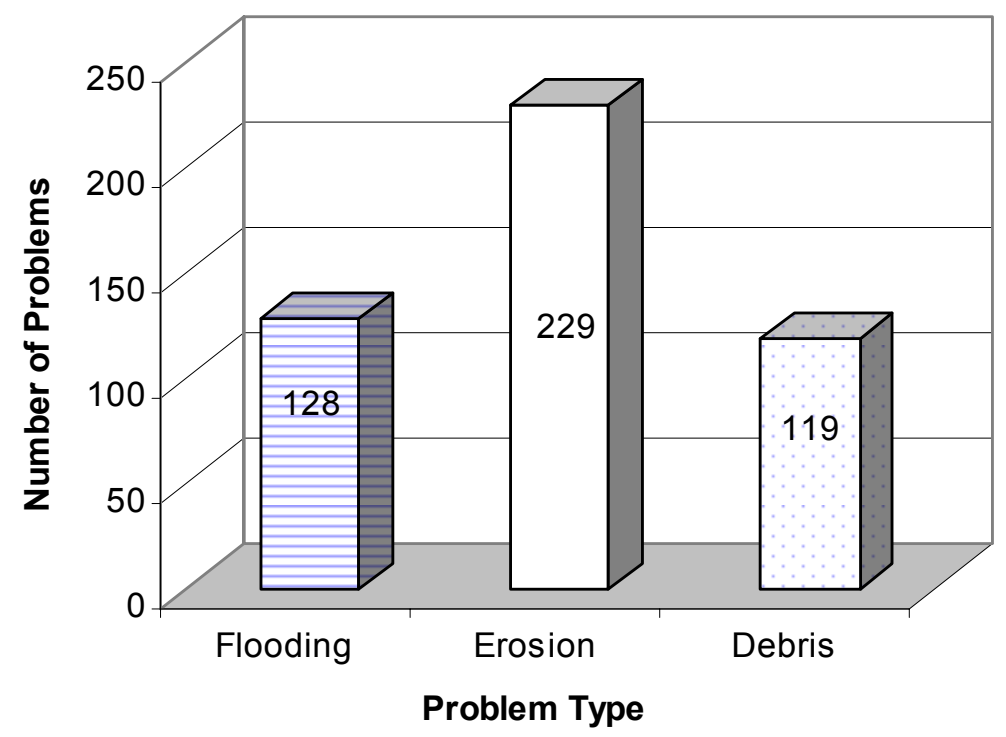

Four specific types of solutions were developed for the intercommunity drainage problems in each watershed: conveyance, storage/detention, floodplain management, and a combination of the previous three types of solutions. Table 14.4 lists feasible technology options considered in the RIDE Study. The following alternatives were considered:

Conveyance improvements (Alternative A) are structural measures that control flooding by moving runoff away from buildings and roadways, such 
as widening channels and constructing new drainage infrastructure (e.g., culverts, bridges, or storm sewers).

Storage/detention improvements (Alternative B) are structural measures that control flooding by holding runoff in facilities such as excavated detention basins, impoundment dams across watercourses, and hydrobrakes in storm drain inlets that promote minor surface ponding along local streets.

Floodplain management (Alternative $C$ ) represents structural and nonstructural measures that separate buildings and roadways from flooding, such as floodplain preservation, flood prevention with berms and walls, and the purchase of flood-prone properties.

Combination improvements (Alternative D) are a logical, cost-effective set of the previous three types of options for the watershed.

Table 14.4 RIDE Study storm water control technologies.

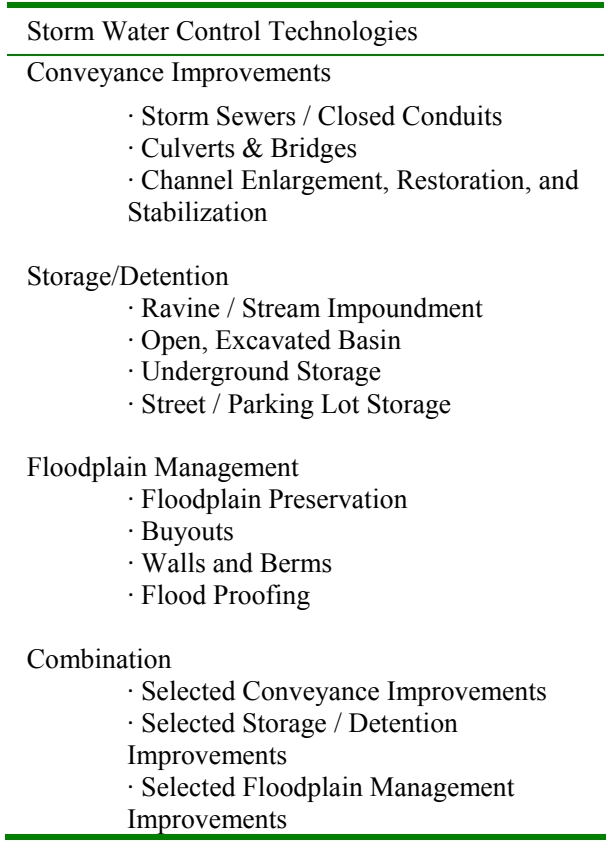

In determining the best solution for each drainage problem, alternatives were evaluated on a watershed-wide basis using the six specific weighted evaluation criteria as shown in Figure 14.12:

- capital and operational costs, 
- effectiveness of drainage improvements,

- compatibility with community interests,

- consistency with regulatory requirements,

- environmental benefits (e.g., water quality enhancement), and

- implementation issues.

The RIDE Study balanced and weighed each of these criteria to select the optimal solutions for problems within each watershed. Regional solutions have been considered where appropriate to promote cost-effective watershedwide benefits. First, a score between 1 and 10 was assigned to each alternative for each evaluation criteria (i.e., the higher the score, the more favorable the alternative). Then, the score was multiplied by a weighting factor assigned to each criterion by the RIDE team, giving an overall evaluation score for the alternative between 1 and 10, whereby the higher the score, the more favorable the alternative.

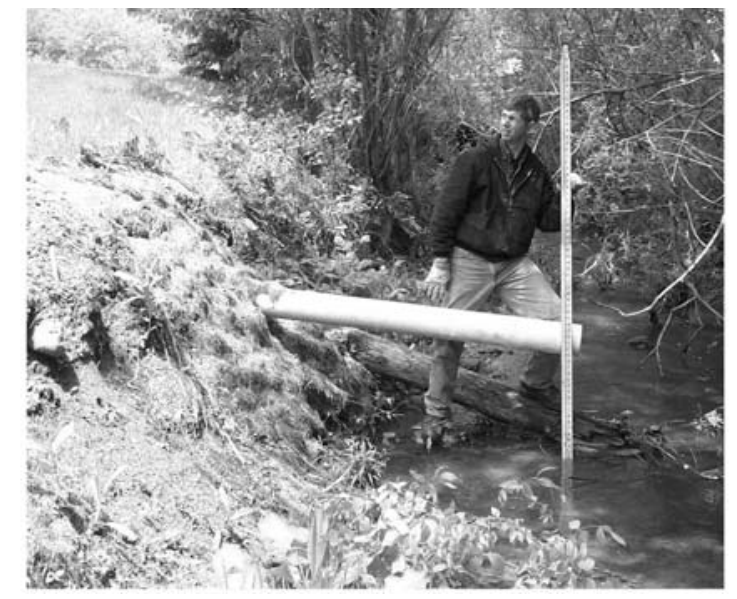

Figure 14.12 Example of a regular stream inspection program.

\subsubsection{Measures Addressing Streambank Erosion}

The stream erosion evaluation concluded that nearly half of the intercommunity streams are subject to moderate to severe erosion. Therefore, a systematic program of structural and nonstructural measures was recommended to address severe and moderate erosion over time. Three major measures are recommended for addressing stream erosion: 
Capital Improvements for Erosion Threatening Structures. Study recommendations generally involved methods that preserve or enhance the stream and riparian habitat. Such solutions are consistent with community NPDES Phase II Storm Water permit requirements, as well as permit requirements for work within streams under Sections 401 and 404 of the Clean Water Act.

Setbacks from all Intercommunity Streams. Stream setback requirements generally rely upon nonstructural measures to separate streams from urban development in a manner that accommodates stream morphologic processes and protects stream habitat. The Summit County (Ohio) Riparian Setback Ordinance provides a model for establishing stream setbacks. Under this ordinance, stream setbacks are set at either the floodplain boundary or a specific width measured from the ordinary high water mark on each side of a stream, whichever is wider. The recommended setback width is $75 \mathrm{ft} .(23 \mathrm{~m})$ on each side of streams within the major drainage system, which are generally those draining an area greater than 0.5 sq. mi. (320 acres or 130 ha). A minimum setback width of $50 \mathrm{ft}$. $(15 \mathrm{~m})$ is recommended on each side of streams draining an area greater than 0.05 sq. mi. ( 32 acres or $13 \mathrm{ha}$ ) and up to 0.5 sq. mi., while a minimum setback width of $30 \mathrm{ft} .(9 \mathrm{~m})$ is recommended on each side of all streams draining an area less than 0.05 sq. mi.. If structures and/or other "non-conforming uses" already exist within the setback, the Summit County ordinance establishes the setback at the existing structure foundation, requiring any redevelopment or addition to be placed further back from the stream.

Replacement and Renewal Program. This program includes a regular stream inspection and maintenance program to track changes in stream erosion and re-evaluate the potential of this erosion to impact structures and habitat. The program also includes a stream restoration program addressing problematic stream erosion in a manner that minimizes impacts to property and improves stream habitat. The RIDE Study encourages use of natural stream restoration techniques to leverage available grant funding and address environmental regulation requirements.

\subsubsection{Measures Preserving Drainage System Capacity}

The recommended solutions to drainage problems presenting an immediate threat will only successfully achieve the desired level of flood and erosion control if the following additional measures are implemented to maintain the capacity of the intercommunity drainage system: 
- Maintain Intercommunity Drainage System. Requirements and estimated costs of a preventive maintenance program for the intercommunity drainage system are provided. This program would remove vegetation, debris, and silt as necessary to achieve its drainage functions, while retaining sufficient biologic and geomorphologic properties to be stable and healthy.

- Preserve Existing Floodplains. The RIDE Study recommends preserving remaining floodplains along the intercommunity drainage system through ordinance modifications and/or easement acquisition. Floodplain preservation retains natural flood storage volumes, allows natural stream morphologic processes to occur, protects stream and riparian habitat, and significantly reduces the capital cost of recommended drainage improvements.

- Control Increased Runoff from Future Development. Storm water detention is recommended to limit future flooding, erosion, and water quality problems in developing areas of the RIDE Study area. The RIDE Study anticipates appropriate controls for future development will be implemented through ordinance modifications and compliance with NPDES Phase II Storm Water Regulations, and that costs will be borne by the property developer.

- Replace and Renew Aging Drainage Infrastructure. The RIDE Study suggests an annual investment in a drainage system renewal program that preserves the structural integrity of the intercommunity drainage system, removing sediments trapped within detention basins, and repairing accelerated erosion of streambeds and streambanks.

\subsection{Next Steps}

Based on the alternatives evaluation described above, capital improvement projects for both flood and erosion control were recommended, including projected program costs and suggested implementation activities in each of the 27 watersheds. At this time, the RIDE Study team is awaiting District board approval of these recommendations and their associated costs.

Following this approval process, the District will seek opportunities to assist their member communities implement these solutions, pursuing available grant funding where available. The District also plans to support 
community compliance activities under NPDES Phase II Storm Water Regulations. In addition, the District will evaluate legal, institutional, and financial aspects related to the implementation of the adopted storm water management program for the RIDE Study area.

\section{References}

CDM Inc., MWH Inc., and WRCE Inc. (2003). Northeast Ohio Regional Sewer District, Regional Intercommunity Drainage Evaluation Study, Cuyahoga River South Drainage Area Report (Draft Report).

Chagrin River Watershed Partners (CRWP) (2003). Chagrin River Watershed Partners website, from http://www.crwp.org/. Chagrin River Watershed Partners.

Cuyahoga County Planning Commission, OH (2002).Cuyahoga Country Greenspace Plan, from http://www.planning.co.cuyahoga.oh.us/green/. Cuyahoga County Planning Commission.

Summit County, OH (2002). Ordinance No. 2002-154 - Riparian Setback Ordinance. Summit County, $\mathrm{OH}$.

United States Environmental Protection Agency (1999). National Pollutant Discharge Elimination System - Regulations for Revision of the Water Pollution Control Program Addressing Storm Water Discharges; Final Rule (64 FR 68722). United States Environmental Protection Agency. 